\title{
Use of fruit bait traps for monitoring of butterflies (Lepidoptera: Nymphalidae)
}

\author{
Jennifer B. Hughes, Gretchen C. Daily and Paul R. Ehrlich ${ }^{1}$ \\ ' Dept. of Biological Sciences, Stanford University, Stanford, CA 94305 USA. Fax (415) 7235920
}

Received 12-I-1998. Corrected 12-V-1998. Accepted 8-VI-1998.

\begin{abstract}
There exists great interest in using fruit-feeding adult nymphalid butterflies to monitor changes in tropical forest ecosystems. We intensively sampled the butterfly fauna of mid-elevation tropical moist forest in southem Costa Rica with fruit bait traps to address a series of practical issues concerning the development of a robust, efficient sampling program. Variation in the number of captures and escapes of butterflies at the traps was better explained by the time of day than by the age of bait. Species' escape rates varied widely, suggesting that short term, less intensive surveys aimed at determining presence or absence of species may be biased. Individuals did not appear to become "traphappy" or to recognize the traps as food sources. Considering the tradeoff between numbers of traps and frequency of trap servicing, the most efficient sampling regime appears to be baiting and sampling the traps once every other day.
\end{abstract}

Key words: butterfly trapping, Costa Rica, monitoring, Nymphalidae, tropical conservation.

Tropical forests are being altered and destroyed at rapid rate, yet the impacts on biodiversity and ecosystem services are only beginning to be understood (Lawton and May 1995, Pimm et al. 1995, Daily 1997). Practical, reliable methods of evaluating changes in biodiversity and ecosystem function are needed to inform public policy (Noss 1990). There is great interest in developing monitoring programs of tropical ecosystems using frugivorous adult butterfly communities sampled with bait traps (Holloway 1980, Lovejoy et al. 1986, Brown 1991, Kremen 1992, Scoble 1992, Sparrow et al. 1994, Daily and Ehrlich 1995). A number of important questions about the utility of this approach remain open, however, including the extent to which the sampling routine can introduce bias into a monitoring program.
We have trapped butterflies extensively in a region of southern Costa Rica in primary and secondary forest and agricultural areas for over 2000 trap days. In previous studies, we used these surveys to address issues such as the applicability of butterflies as indicator species of other taxa and the impact of forest fragmentation on butterfly diversity (e.g., Daily and Ehrlich 1995, Daily and Ehrlich 1996). We have also begun an intensive mark-recapture study to assess the use of forest fragments as corridors by butterflies.

Certainly, bait trapping provides a biased look at the butterfly fauna itself. First, there are many butterfly species that are never captured in the traps. Second, among those captured in the traps, some are probably more strongly attracted than others; thus, the relative 
abundances of species caught almost certainly do not reflect the relative abundances of fruitfeeding species in the region. Yet despite these drawbacks, bait trapping offers a useful way to monitor changes in species abundances over time, to compare species composition and abundances between sites, and to track the movement of individuals.

Using the relatively well-known butterfly fauna of mid-elevation tropical moist forest in southern Costa Rica (e.g., DeVries 1987), we designed a sampling regime to determine: (1) what time of day butterflies typically enter the traps; (2) the propensity of different species to escape; (3) the influence of age of bait on trapping and escape rate; (4) the tendency of individuals to become "trap-happy;" and (5) the amount of information lost by less intensive surveys.

We hope that this preliminary study sheds light on the most obvious and easily addressed problems with the fruit-trapping method. While our main purpose was to provide background for refining trapping techniques, we also sampled in two habitat types to see if there were striking differences in the faunas present. This study is not designed to examine these potential differences in detail, however. Many researchers have addressed the influence of habitat type on butterfly assemblages elsewhere (e.g., Brown and Hutchings 1997, DeVries et al. 1997).

\section{MATERIALS AND METHODS}

Area: The study was conducted in the vicinity of the Las Cruces Biological Field Station of the Organization of Tropical Studies (OTS/OET), Coto Brus, Costa Rica in March and April 1996. The Las Cruces forest consists of primary Pacific mid-elevation forest (211 ha) and mature second growth (16 ha) adjacent to the managed Wilson Botanical Garden.

Trap design: We used 18 Van SomerenRydon traps (DeVries 1987), cylinders of grey nylon netting $(65 \mathrm{~cm}$ high and $25 \mathrm{~cm}$ in diameter) sewn onto a frame of two wire hoops, closed and covered by a plastic dish at the top, open at the bottom, and with a Velcro-fastened slit in the side for removing trapped insects. Each trap had a sheet of plywood $\left(40 \times 40 \mathrm{~cm}^{2}\right)$ suspended a few centimeters below the netting, with an inverted disposable plastic dish $15 \mathrm{~cm}$ in diameter in the center on which the bait was placed. The bait was covered with a second inverted dish perforated with holes roughly 1 $\mathrm{cm}$ in diameter and fixed into position with string to prevent robbery by birds and mammals yet still permit feeding by butterflies. The bait consisted of mashed, rotting bananas, a liberal dose of molasses, and a dash of rum. The bait was prepared on the afternoon prior to the morning of use and typically became well fermented in that time.

Trap location and monitoring scheme: Nine traps were placed in mature second growth of the Las Cruces forest (hereafter forest sites), and nine traps were placed on a farm of coffee and overgrown pasture adjacent to the Wilson Botanical Garden (hereafter pasture sites). Each trap was checked three times per day: early morning (05:30 - 08:00), midday (10:00 - 13:30), and late afternoon (15:00 - 17:00). Dawn was at 05:30 and dusk at 17:30. The traps were baited every other day during the morning check, alternating each day between the forest and pasture sites. The traps were open for 14 days and baited seven times. All butterflies were cleared from the trap at each baiting, but not before.

Each butterfly captured was identified to species, and all but the superabundant species in the genus Cissia (Satyrinae) were uniquely marked with a felt pen. We would not have been able to check the traps as often with the additional time required to mark all the Cissia individuals.

Individuals that were captured and had been previously marked were noted as recaptures. Numbers of captures include both newly captured and recaptured individuals. Marked butterflies were recorded as escapes if they disappeared from the trap between trap checks; some individuals (five) escaped from the hand during marking, but these were not included in the analysis of escape frequencies. 
After feeding on the bait, the butterflies usually hung quietly from the top or sides of the trap. Handling often caused them to fly around inside the trap and sometimes escape. Therefore, immediately after marking any newly captured butterflies, the trap was held closed until all the butterflies were resting again. Once a butterfly was marked, we did not handle it during subsequent trap checks.

Statistical analyses: We used the KruskalWallis statistic to test for differences between both capture and escape rates across the time of day and Wilcoxon signed-rank tests to examine the effect of bait age. For these analyses, the data were pooled across all the days sampled and the replicates were the eighteen traps. To test whether more individuals were recaptured than expected by chance, we compared the distribution of the number of times each individual was captured to the Poisson using a chi-square test distribution (combining the categories which had expected values below one). To calculate evenness of species abundance in the different habitats, we used the index $\mathrm{J}^{\prime}=-\mathrm{I}^{\prime} p_{i}$ $\ln \left(p_{i}\right) / 1 \mathrm{nS}$, where $p_{i}$ is the proportional abundance of species $i$, and $S$ is the total number of species (Pielou 1966).

\section{RESULTS}

A total of 337 individuals representing 43 species of butterflies were caught (Table 1). All species were fruit-feeding nymphalids of the subfamilies Charaxinae, Nymphalinae, Morphinae, Brassolinae, and Satyrinae. Nine species of Cissia were captured (Table 2), and this genus comprised $54 \%$ of the individuals captured. We recorded 185 non-Cissia captures; of these, 146 were newly captured and marked individuals, 34 were recaptured, and five escaped before we could mark them.

Time of day: The number of individuals (excluding Cissia species) captured by the traps before the morning, midday, and afternoon observations differs significantly (KruskalWallis; $H=11.092, p=0.004$, d.f.=2) (Table 3). Most of the species captured are described as diurnal in the literature (e.g., DeVries 1987). Our results confirmed this; many more individuals arrived during the day (between morningmidday and midday-afternoon checks), than at either dusk or dawn (between the afternoon and morning checks). The few exceptions correspond with the known periods of activity of the species involved. For instance, Opsiphanes

\section{TABLE 1}

Number and percent of captures by species trapped, number of captures that were recaptures, number of captures by time of day, and percent of captures that escaped.

Species

Charaxinae
Archaeoprepona demophoon
Archaeoprepona demophon
Archaeoprepona meander
Memphis arginussa
Memphis beatrix
Memphis chaeronea
Memphis glycerium
Memphis laura
Memphis niedhoeferi
Memphis oenomais
Memphis orthesia
Memphis xenocles
Prepona omphale
Siderone syntyche

$$
\text { number of captures }
$$

forest pasture total percent

of total number of

captures by time of day

captures recaptures moming midday afternoon percent escaped

$\begin{array}{cccc}1 & 6 & 7 & 3.7 \\ 1 & 2 & 3 & 1.6 \\ 1 & 2 & 3 & 1.6 \\ 3 & 9 & .12 & 6.4 \\ 0 & 2 & 2 & 1.1 \\ 0 & 7 & 7 & 3.7 \\ 0 & 20 & 20 & 10.7 \\ 0 & 1 & 1 & 0.5 \\ 1 & 0 & 1 & 0.5 \\ 0 & 3 & 3 & 1.6 \\ 0 & 2 & 2 & 1.1 \\ 10 & 26 & 36 & 19.3 \\ 1 & 6 & 7 & 3.7 \\ 0 & 1 & 1 & 0.5\end{array}$

1
0
0
1
1
2
6
0
0
0
0
8
0
0

$\begin{array}{ll}0 & 5 \\ 0 & 1 \\ 0 & 1 \\ 0 & 7 \\ 0 & 1 \\ 0 & 3 \\ 0 & 12 \\ 0 & 1 \\ 0 & 0 \\ 0 & 2 \\ 0 & 1 \\ 3 & 18 \\ 1 & 6 \\ 0 & 1\end{array}$




\begin{tabular}{|c|c|c|c|c|c|c|c|c|c|}
\hline \multicolumn{10}{|l|}{ Nymphalinae } \\
\hline Callicore pacifica & 1 & 0 & 1 & 0.5 & 0 & 0 & 1 & 0 & 100 \\
\hline Catonephele mexicana & 2 & 1 & 3 & 1.6 & 0 & 1 & 1 & 1 & 66.7 \\
\hline Catonephele numilia & 0 & 6 & 6 & 3.2 & 0 & 0 & 2 & 3 & 33.3 \\
\hline Colobura dirce & 0 & 7 & 7 & 3.7 & 2 & 0 & 2 & 5 & 28.6 \\
\hline Hamadryas amphinome & 0 & 1 & 1 & 0.5 & 0 & 0 & 0 & 1 & 0 \\
\hline Hamadryas feronia & 0 & 4 & 4 & 2.1 & 2 & 0 & 2 & 2 & 25.0 \\
\hline Hamadryas fornax & 1 & 1 & 2 & 1.1 & 0 & 0 & 2 & 0 & 0 \\
\hline Hamadryas guatemalena & 0 & 2 & 2 & 1.1 & 0 & 0 & 2 & 0 & 50.0 \\
\hline Historis acheronta & 0 & 2 & 2 & 1.1 & 0 & 0 & 2 & 0 & 100 \\
\hline Historis odius & 0 & 4 & 4 & 2.1 & 1 & 0 & 3 & 1 & 25.0 \\
\hline Smyrna blomfildia & 0 & 7 & 7 & 3.7 & 2 & 0 & 7 & 0 & 14.3 \\
\hline \multicolumn{10}{|l|}{ Morphinae } \\
\hline Morpho peleides & 8 & 0 & 8 & 4.3 & 3 & 0 & 5 & 3 & 100 \\
\hline Morpho theseus & 0 & 5 & 5 & 2.7 & 2 & 0 & 5 & 0 & 80.0 \\
\hline \multicolumn{10}{|l|}{ Brassolinae } \\
\hline$C$ aligo atreus & 5 & 0 & 5 & 2.7 & 1 & 2 & 3 & 0 & 0 \\
\hline Caligo eurilochus & 2 & 0 & 2 & 1.1 & 0 & 1 & 0 & 1 & 0 \\
\hline Eryphanis aesacus & 0 & 1 & 1 & 0.5 & 0 & 0 & 0 & 1 & 100 \\
\hline Opsiphanes tamarindi & 0 & 3 & 3 & 1.6 & 0 & 3 & 0 & 0 & 33.3 \\
\hline \multicolumn{10}{|l|}{ Satyrinae (excluding Cissia) } \\
\hline Chloreuptychia arnaea & 3 & 0 & 3 & 1.6 & 0 & 1 & 0 & 3 & 33.3 \\
\hline Taygetis andromeda & 2 & 1 & 3 & 1.6 & 1 & 1 & 2 & 0 & 33.3 \\
\hline Taygetis virgilia & 8 & 5 & 13 & 7.0 & 1 & 10 & 3 & 0 & 46.2 \\
\hline Totals: & 50 & 135 & 185 & 100 & 34 & 23 & 101 & 61 & 39 \\
\hline
\end{tabular}

tamarindi (Brassolinae) is considered crepuscular, and all new arrivals were observed in the morning. Caligo atreus (Brassolinae) is also crepuscular and was captured only in the morning and at midday. Like Caligo atreus, Taygetis virgilia and Taygetis andromeda (Satyrinae) were also observed in the morning and midday traps only, although their time of peak activity is not reported in DeVries (1987). Of the remaining 29 non-Cissia species, the vast majority of new captures were made at midday and afternoon (Table 1).

Of the 180 marked captures, 73 (41\%) escaped between recording them and clearing of the trap. The number of individuals that escaped did not vary significantly with respect to time of day (Kruskal-Wallis; $H=5.002$, $p=0.082$, d.f.=2), although escapes followed the same trend as capture activity; that is, most escaped during the day rather than between dusk and dawn (Table 3).

\section{TABLE 2}

The location, number, and percentage Cissia species captures.

\begin{tabular}{ccc} 
Species & \multicolumn{2}{c}{ number of captures $\begin{array}{l}\text { percent } \\
\text { of total } \\
\text { captures }\end{array}$}
\end{tabular}

\begin{tabular}{|c|c|c|c|c|}
\hline Cissia gigas & 1 & 1 & 2 & 1.1 \\
\hline Cissia hermes & 2 & 27 & 29 & 15.6 \\
\hline Cissia hesione & 23 & 9 & 32 & 17.2 \\
\hline Cissia metaleuca & 3 & 2 & 5 & 2.7 \\
\hline Cissia labe & 1 & 6 & 7 & 3.8 \\
\hline Cissia polyphemus & 6 & 1 & 7 & 3.8 \\
\hline Cissia pseudoconfusa & 0 & 2 & 2 & 1.1 \\
\hline Cissia renata & 0 & 29 & 29 & 15.6 \\
\hline Cissia satyrina & 56 & 17 & 73 & 39.2 \\
\hline
\end{tabular}




\section{TABLE 3}

Percentage of captures and escapes at the three observation times and the Kruskal-Wallis statistics.

\begin{tabular}{lcccccc} 
& \multicolumn{3}{c}{$\begin{array}{c}\text { percent individuals } \\
\text { captured/escaped in } \\
\text { morning }\end{array}$} & $\begin{array}{c}\text { Kruskal- } \\
\text { Wallis }\end{array}$ \\
captures $(n=187)$ & 11.8 & 54.5 & 33.7 & 11.092 & 0.004 \\
& & & & & \\
escapes $(n=74)$ & 23.0 & 40.5 & 36.5 & 5.002 & 0.082
\end{tabular}

TABLE 4

Percentage of captures and escapes at each check during the two day baiting period and the Wilcoxon signed rank test statistics.

\begin{tabular}{lcccccccccc} 
& \multicolumn{3}{c}{ day one } & & & day two & \multicolumn{4}{c}{ Wilcoxon signed-rank $Z$} \\
& morning & midday & afternoon & morning & midday & afternoon & morning & midday & afternoon \\
captures $(n=187)$ & 5.9 & 37.4 & 16.0 & 5.9 & 17.1 & 17.6 & -0.273 & -2.752 & 0.359 \\
& & & & & & & & $p=0.785$ & $p=0.006$ & $p=0.719$ \\
escapes $(n=74)$ & 9.5 & 5.4 & 17.6 & 13.5 & 35.1 & 18.9 & -0.647 & 2.898 & 0.575 \\
& & & & & & & & $p=0.518$ & $p=0.004$ & $p=0.565$
\end{tabular}

Propensity to escape: There were not enough escapes to permit statistical testing for differences in escape rates among species; escape rates across species varied greatly, however (Table 1). The species in the genus Morpho stand out as having exceptionally high escape rates. All eight times Morpho peleides was captured, the individuals escaped before the traps were rebaited and emptied. Four out of five times Morpho theseus escaped. In our experience with thousands of trap clearances in the same area, the Morpho are uniquely skilled at escaping; they detect the approach of a person from meters away (even when he or she is taking pains to move slowly and cautiously) and quickly walk out from under the trap and fly away.

Age of bait: The traps were baited in the early morning every 48 hours. To examine the effect of the age of bait, we compared the number of captures obtained on the first and second days of the baiting period. Except for the first few hours after baiting, the age of the bait seems to have no effect on the number of captures. The number of individuals captured between the morning and midday trap checks on day one $(37.4 \%)$ is significantly higher than the number caught during the same time period of day two $(17.1 \%)$ (Wilcoxon signed-rank; $Z=-2.752$, $p=0.006$, d.f. $=18$ ), whereas the number of individuals captured at the other observation times is not significantly different between day one and day two of the baiting period (Table 4). 
address to two aspects of this problem. We refer to "trap-happiness" as a tendency of individuals to return repeatedly to the same trap. We define a separate term, "trap-recognition," as the tendency of individuals to recognize any trap as a food source. There is no sign of either trap-happiness or trap-recognition. The frequency of recaptures falls off sharply with increasing number of captures: 146 individuals were captured once, 27 twice, 5 three times, and 1 four times. This distribution is not significantly different from a Poisson distribution $\left(X^{2}=2.049\right.$, $p=0.355$, d.f. $=2$ ). In other words, individuals are not being recaptured more than expected by chance. The frequent movement between traps is further evidence against trap-happiness; 15 out of 34 (44\%) of the recaptured individuals moved between different traps. The only individual that was captured four times was Memphis glycerium, and the captures were at three different traps. Detecting significant differences among species in their tendency to be recaptured proved difficult because of the small number of individuals recorded. It is interesting to note, however, that while they have a greater tendency to escape, Morpho peleides and $M$. theseus also appear more likely to show traprecognition than the other species; of the eight $M$. peleides captures recorded, three were recaptures, and two of the five $M$. theseus captures were recaptures. Trap-recognition in these species has been previously noted (Young 1973).

Sampling intensity: We can explore the efficiency of different sampling intensities by comparing our actual routine (checking three times a day) to less intensive routines by removing the results of some of the trap checks. For instance, if we had checked the traps only every morning, we would have recorded $76 \%$ of the captures and $91 \%$ of the species richness that we detected in the more intensive routine. If we had checked the traps only when baiting every two days, more than half (55\%) of the individuals and most (85\%) of the species richness of the actual routine would have been represented. We can also directly compare the efficiency of daily versus every-two-day sampling; checks every other day would have recorded $72 \%$ of the individuals and $94 \%$ of the species from daily observations.

Differences between habitats: More butterflies were caught in the pasture site than in the forest (229 and 142 captures, respectively). In particular, more Cissia individuals were captured in the pasture, although the percentage of Cissia captured was lower in the pasture than the forest (41\% versus 65\%). Both species richness and Pielou's evenness index were higher in the pasture than forest $\left(37\right.$ and 23 species, $J^{\prime}=$ 0.851 and 0.711 , respectively). Excluding the Cissia species, a genus thought to be associated with human disturbance (Singer and Ehrlich 1991), species numbers remained higher in the pasture (28 versus 16 species), although Pielou's index was then similar for the two habitats: 0.866 in the pasture and 0.876 in the forest.

\section{DISCUSSION}

A number of practical suggestions about these trapping methods can be offered on the basis of this study. For instance, variation in captures and escapes seems to be explained well by the time of day, rather than bait age, except immediately after baiting. Thus, baiting every day would only slightly increase the number of captures (by an estimated 20\% from this study) and does not seem likely to alter the qualitative results of a diversity inventory. From previous experience, we suspect that baiting every three days would not be sufficient, as rain and evaporation of the alcohol appear to greatly diminish the attractiveness of the bait by the third day. Considering the time required to prepare the bait and rebait the traps, baiting every two days seems to offer a reasonable compromise between effort and information. Furthermore, only a small amount of information would have been lost by checking the traps only when baiting compared to checking daily or to checking three times a day. As with baiting every two days, reducing the sampling to every other day probably would not change the qualitative 
results of an inventory. For most studies then, the effort used to bait or check the traps more often would be better allocated to sampling in more habitats or trapping over a longer time period.

Perhaps not unexpectedly, escape rates appear to vary greatly among species. Thus, infrequent trap checks and short term trapping may lead to an undersampling of species with high rates of escape. Certainly, further work is necessary to refine knowledge of species differences in bait attractiveness, trap-happiness, and trap-recognition. Other variables that we did not address here, but that also surely influence the results of a trapping program, are seasonality and trap height; however, within a given study it should be practical to standardize these factors.

An examination of the list of species caught in the two habitats reveals striking differences in habitat preferences among some species (Tables 1 and 2). For instance, within the Cissia butterflies, $C$. renata was found only in pasture, whereas most of the $C$. satyrina and $C$. hesione individuals were captured in forest. These results correspond well with habitat preferences noted in DeVries (1987). Similarly, Morpho theseus was trapped only in pasture and $M$. peleides, only in forest. In contrast to the Cissia species, however, both of the Morhpo species are thought to be associated with forest habitats (Young 1973). Although the sample size here is small, this pattern highlights an important suite of questions that remain to be answered regarding the use of open, human-dominated habitats by forest species (Daily in press). How many of the species found in open areas could survive without forest nearby? Are forest species entering open country during part of the day, perhaps when temperature and humidity conditions more likely resemble the forest understory? From this study, it appears that very few butterfly species, forest specialists or otherwise, are moving in open areas at dawn and/or dusk. Perhaps midmorning is simply a time of high-activity for forest butterfly species, and they are more likely to make exploratory flights then. These deceptively simple questions are crucial for addressing issues of tropical biodiversity conservation.

\section{ACKNOWLEDGEMENTS}

We are grateful to Ellyn Bush, Scott Daily, Tom Davis, and especially to George Burtness for reliable assistance and enthusiasm in the field. We thank Mark Tanaka for statistical advice and Richard Vane-Wright for insightful comments on an earlier draft of the manuscript. Edwin and Maria Vindes painstakingly made the traps. Luis Diego Gomez and Gail HewsonGomez of the OTS Las Cruces Research Station graciously provided hospitality and assistance. This work was supported by the Pew Charitable Trusts, the Winslow and Heinz Foundations, and the generosity of Peter and Helen Bing. Abstract: There exists great interest in using fruit-feeding adult nymphalid butterflies to monitor changes in tropical forest ecosystems. We intensively sampled the butterfly fauna of midelevation tropical moist forest in southern Costa Rica with fruit bait traps to address a series of practical issues concerning the development of a robust, efficient sampling program. Variation in the number of captures and escapes of butterflies at the traps was better explained by the time of day than by the age of bait. Species' escape rates varied widely, suggesting that short term, less intensive surveys aimed at determining presence or absence of species may be biased. Individuals did not appear to become "trap-happy" or to recognize the traps as food sources. Considering the tradeoff between numbers of traps and frequency of trap servicing, the most efficient sampling regime appears to be baiting and sampling the traps once every other day

\section{RESUMEN}

Existe gran interés en monitorear las poblaciones de mariposas tropicales mediante trampas cebadas. Estudiamos de manera intensiva una localidad de bosque tropical húmedo de mediana altitud en el sur de Costa Rica. La variación en el número de capturas y escapes de las trampas se asoció más con la hora del día que con la edad del cebo. Los mues reos a corto plazo son poco confiables pues las especies difieren en su tasa de escapes. Los individuos no parecieron hacerse adictos a las trampas o reconocerlas como fuentes de alimentación. La atención a las trampas de día de por medio resultó eficiente. 


\section{REFERENCES}

Brown, J., K.S. \& R. W. Hutchings. 1997. Disturbance, fragmentation, and the dynamics of diversity in Amazonian forest butterflies, p. 616. In W. F. Laurance \& R. O. Bierregaard (eds). Tropical Forest Remnants. University of Chicago, Chicago, Illinois.

Brown, K. S., Jr. 1991. Conservation of neotropical environments: insects as indicators, p. 349-404. In N. M. Collins and J. A. Thomas (eds). Conservation of Insects and their Habitats. Academic, San Diego, California.

Daily, G. C. 1997. Nature's Services: Societal Dependence on Natural Ecosystems. Island Press, Washington, D.C., $392 \mathrm{p}$.

Daily, G. C. in press. Countryside biogeography and managing natural capital. In P. Raven (ed). Nature and Human Society: The Quest for a Sustainable World. National Academy Press, Washington, D.C.

Daily, G. C. \& P. R. Ehrlich. 1995. Preservation of biodiversity in small rainforest patches: rapid evaluations using butterfly trapping. Biodiver. Conserv. 4: 35-55.

Daily, G. C. \& P. R. Ehrlich. 1996. Noctumality and species survival. Proc. Nat. Acad. Sci. 93: 11709-11712.

DeVries, P. J. 1987. The Butterflies of Costa Rica and their Natural History. Princeton University, Princeton, New Jersey.

DeVries, P. J., D. Murray \& R. Lande. 1997. Species diversity in vertical, horizontal, and temporal dimensions of a fruit-feeding butterfly community in an Ecuadorian rainforest. Biol. J. Linn. Soc. 62: 343-364.

Holloway, J. D. 1980. Insect surveys - an approach to environmental monitoring. Congr. Naz. Ital. Entomol. : 239-261.
Kremen, C. 1992. Assessing the indicator properties of species assemblages for natural areas monitoring. Ecol. Applic. 2: 203-217.

Lawton, J. H. \& R. M. May. 1995. Extinction Rates. Oxford University, Oxford, UK, 233 p.

Lovejoy, T. E., R. O. Bierregaard, A. B. Rylands, J. R. Malcolm, C. E. Quintela, L. H. Harper, K. S. Brown, Jr., A. H. Powell, G. V. N. Powell, H. O. R. Schubart \&M. B: Hays. 1986. Edge and other effects of isolation on Amazon forest fragments, p. 257-285. In M. E. Soulé (ed). Conservation Biology: The Science of Scarcity and Diversity. Sinauer, Sunderland, Massachessetts.

Noss, R. F. 1990. Indicators for monitoring biodiversity: a hierarchical approach. Conserv. Biol. 4: 355-364.

Pielou, E. C. 1966. The management of diversity in different types of biological collections. J. Theor. Biol. 13: 131-144.

Pimm, S. L., G. J. Russell, J. L. Gittleman \& T. M. Brooks. 1995. The future of biodiversity. Science 269: $347-350$.

Scoble, M. J. 1992. The Lepidoptera: Form, Function, and Diversity. Oxford University, Oxford, UK.

Singer, M. \& P. R. Ehrlich. 1991. Host specialization of satyrine butterflies and their responses to habitat fragmentiation in Trinidad. J. Res. Lepid. 30: 248-256.

Sparrow, H. R., T. D. Sisk, P. R. Ehrlich \& D. D. Murphy. 1994. Techniques and Guidelines for Monitoring Neotropical Butterflies. Conserv. Biol. 1: 334-341.

Young, A. M. 1973. Studies on comparative ecology and ethology in adult populations of several species of Morpho butterflies (Lepidoptera: Morphidae). Stud. Neotr. Fauna 8: 17-50. 